\title{
A comparative study of propofol based total intravenous anesthesia and sevoflurane based volatile induction and maintenance anesthesia on post-operative recovery profile in elective tonsillectomy
}

\author{
Sarfaraz Ahmed', Athar Siddique ${ }^{2}$, Kalyani Malshetwar ${ }^{3}$, Nitesh Nagbhire ${ }^{4}$, \\ S. D. Yennawar ${ }^{5}$ \\ ${ }^{1,3}$ Assistant Professor, ${ }^{2,4}$ Senior Resident, ${ }^{5}$ Ex Head, Department of Anaesthesiology, Dr. Shankarrao Chavan \\ Government Medical College and Hospital, Nanded, Maharashtra, India
}

\begin{abstract}
Background: Tonsillectomies are common surgeries in day-to-day surgery practice particularly in pediatric age group. Recent trend is to conduct tonsillectomy surgery on a day care basis. It is important to use the best anesthetic option with the least recovery time to reduce the hospital stay of patient. Aims and Objectives: The aim of the study was to compare recovery profile and side effects of Sevoflurane and Propofol as an anesthetic agent for tonsillectomy. Materials and Methods: A total of 60 patients undergoing elective tonsillectomy were selected for the study. Each patient was randomly allocated to either the propofol (Group P) or the sevoflurane group (Group S). Time of surgery (From start to end of surgery), time of anesthesia (From the start of induction to end of surgery), time between the end of anesthesia and the spontaneous eye opening, and time between the end of anesthesia and the following of verbal commands. Time to extubation, time between the end of anesthesia, and the orientation to his or her name and the incidence of post-operative nausea and vomiting were compared in both the groups. Results: The eye opening in Group P patients was found to be $8.9+1.21 \mathrm{~min}$ and that in Group S was $6.6+1.25$ which was found to be statistically significant. The following of verbal commands in Group P was found to occur at $10.13+1.28 \mathrm{~min}$, while that in Group $S$ was found to be at $7.63+1.25 \mathrm{~min}$, which was statistically significant. The time for extubation in Group $P$ was found to be $11.17+1.29 \mathrm{~min}$, while that in Group $\mathrm{S}$ was found to be $8.67+1.24 \mathrm{~min}$, which was statistically significant. The duration for complete orientation in Group P was found to be $12.2+1.27 \mathrm{~min}$, while that in Group $\mathrm{S}$ was found to be $9.43+1.04 \mathrm{~min}$, which came out to be statistically significant. Hemodynamic parameters were found to be comparable in both the groups with no statistically significant difference in between then at any point of time $(P>0.05)$. Conclusion: Sevoflurane is a useful alternative to propofol in providing anesthesia where rapid emergence and recovery of cognitive functions are desired.
\end{abstract}

Access this article online

Website:

http://nepjol.info/index.php/AJMS DOI: 10.3126/ajms.v12i12.39839

E-ISSN: 2091-0576

P-ISSN: 2467-9100

Copyright (c) 2021 Asian Journal of Medical Sciences

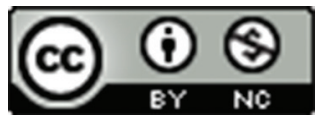

This work is licensed under a Creative Commons Attribution-NonCommercial 4.0 International License.

Key words: Day care surgeries; Propofol; Recovery; Sevoflurane; Tonsillectomy

\section{INTRODUCTION}

Tonsillitis is a common occurrence particularly in pediatric age group. Tonsillectomy with or without adenoidectomy is a long practiced and one of the most frequently performed surgical procedures in pediatric age group worldwide. ${ }^{1}$ The number has declined by approximately $50 \%$ from about 1.4 million in 1959 to about 2 lakh per 
year till date. Although a commonly performed procedure, it poses a great challenge to the surgeon as well as the anaesthesiologist and is associated with a substantially increased risk of morbidity and mortality. ${ }^{2}$

The rise in incidence of tonsillectomy is one of the major phenomenon, around 200,000 tonsillectomies are done annually in India. Obstructive sleep apnea is marked by interruptions in breathing while asleep and is common among children with enlarged tonsils or adenoids. ${ }^{3}$ The absolute indications of the procedure are enlarged tonsils with features of upper airway obstruction, dysphagia, sleep disorders, peritonsillar abscess not adequately responding to medical management, febrile seizures due to tonsillitis, and tonsillar pathology requiring biopsy for a definitive diagnosis. ${ }^{4}$

Recent trend is to conduct tonsillectomy surgery on a day care basis. It is important to use the best anesthetic option with the least recovery time to reduce the hospital stay of patient. Ambulatory anesthesia is one administered for elective surgical procedure performed on carefully selected patients, which is undertaken with all its constituent elements (admission, surgery, and discharge home) on the same day. It is also referred to as day case, day care or outpatient anesthesia and more recently office-based anaesthesia. ${ }^{5}$ Ambulatory anesthesia is a rapidly growing subspecialty. Although its history is as old as the history of general anesthesia itself, it has emerged as a recognized concept and is evolving over the past couple of decades. Anesthetic agents today have been designed and marketed to meet specific niche criteria for ambulatory anesthesia. Among the agents available in India, propofol and sevoflurane have increased the ability of the anaesthesiologist to provide a successful day care experience. A common strategy used in routine clinical practice is to perform the induction with an intravenous formulation (such as propofol) and to continue maintenance with an inhaled agent (such as sevoflurane). While numerous studies have been published comparing inhaled versus intravenous agents for the induction and maintenance of anesthesia in several surgical procedures, study protocols vary with regard to pre-medication, inhalational agents, fresh gas flow rates, additional opioids usage, and the type and duration of surgery. ${ }^{6}$

Sevoflurane and propofol are the agents that can be used for day care surgeries with minimal side effects and early recovery. ${ }^{7}$ Sevoflurane has many features of an ideal inhalational agent; its low blood-gas solubility and nonpungent smell suggest a smooth, uncomplicated and rapid induction of, and emergence from, anesthesia. Sevoflurane is an attractive option for "volatile Induction maintenance anesthesia" which is proposed to prevent the problems associated with the transition phase between intravenous induction and inhalational maintenance. These properties may make sevoflurane especially suitable for day surgery. The pharmacokinetics of propofol allows rapid induction of anesthesia, adequate maintenance, and rapid recovery of consciousness and reduces post-operative morbidity such as nausea, vomiting, and respiratory depression. These two general anesthesia procedures are used in oral and maxillofacial surgeries for the realization of patient comfort and/or invasive surgery application. ${ }^{8}$

During the recovery period, vital finding changes encountered in the follow-up, post-operative pain and postoperative nausea vomiting are among the post-operative complications frequently encountered. Post-operative complication frequency in the patients, their recovery periods and their states to be able to go to their service departments could display differences depending on surgery and anesthesia procedures. ${ }^{9}$

The present study will help in making a choice between these two agents on the basis of their recovery profile and side effects to facilitate tonsillectomy as a day care surgery.

\section{Aims and objectives}

The aim of the study was to compare recovery profile and side effects of Sevoflurane and Propofol as an anesthetic agent for tonsillectomy.

\section{MATERIALS AND METHODS}

The study was prospective randomized comparative single center study conducted in the department of anesthesiology of Dr Shankarrao Chavan Government Medical College and Hospital Vishnupuri Vanded. Institutional ethical committee approved the study (vide letter no SCGMC/217/03/17). The period of study was from January 1, 2018, to June 30, 2020. A total of 60 patients undergoing elective tonsillectomy were selected for the study. All the patients were assessed and those with normal clinical, biochemical, radiological, and hematological parameters were selected. Informed written consent was obtained from all the patients and parents in case of minor.

A total of 60 patients were selected for the study. Each patient was randomly allocated to either the propofol or the sevoflurane group. Randomization was done using a computer-based table of random numbers. The groups were named:

Group P - Consisted of 30 patients in whom induction and maintenance was done with intravenous anesthetic agent propofol.

Group S - Consisted of 30 patients in whom induction and maintenance was done with inhalational anesthetic agent sevoflurane. 
A thorough pre anesthetic evaluation was done including history and general examination. All patients were kept nil per oral before surgery according to standard protocol. Procedure was explained to the patient and informed consent was obtained. After shifting the patient to Operation theater an intravenous drug line was secured with $20 \mathrm{G}$ venous cannula in the non-dominant arm and an infusion of ringer lactate solution was started. Intraoperative monitoring devices such as electrocardiography, pulse oximetry, non-invasive blood pressure, and end-tidal carbon dioxide monitor were attached to patient. All the patients were premedicated with Inj. Glycopyrrolate $0.01 \mathrm{mg} / \mathrm{kg}$ I.V, Inj. Midazolam $0.05 \mathrm{mg} / \mathrm{kg}$ IV. The patients were not given any IM premedication. Since many large randomized controlled trials have concluded that there is no rationale for the prophylactic administration of antiemetic drugs in oral and maxillofacial surgical procedures so prophylactic antiemetic were not given. They were assessed with particular attention to any contraindications. The tests for recovery and the importance of strictly following instructions were emphasized.

\section{Conduct of anesthesia}

Group P (PROPOFOL GROUP): 30 patients. These patients were induced with bolus injection of propofol $3 \mathrm{mg} / \mathrm{kg}$ IV and intubated with $0.5 \mathrm{mg} / \mathrm{kg}$ atracurium. After confirming and securing the endotracheal tube in position, they were connected to the closed circuit with nitrous oxide and oxygen in 60:40 ratio to maintain normocapnia. Immediate post-intubation, this group of patients received a continuous infusion of propofol $100-250 \mathrm{mcg} / \mathrm{kg} / \mathrm{min}$ to maintain an adequate depth of anesthesia as judged by clinical signs and hemodynamic responses to surgical stimuli.

Group S (SEVOFLURANE GROUP): 30 patients. These patients were induced with sevoflurane $7 \%$ by patientcontrolled inhalation induction, that is, spontaneous ventilation and intubated with $0.5 \mathrm{mg} / \mathrm{kg}$ atracurium. After confirming and securing the endotracheal tube in position, they were connected to the closed circuit with nitrous oxide and oxygen in 60:40 ratio to maintain normocapnia with sevoflurane $2-3 \%$ to maintain adequate depth of anesthesia.

Throughout the procedure, heart rate, $\mathrm{SPO}_{2}$, and blood pressure were monitored and recorded at regular intervals and ECG was monitored continuously. All patients were given appropriate maintenance fluid in form of IV Ringer lactate and were continued in the post-operative period until they start taking oral fluids. For pain management, Inj. Paracetamol $15 \mathrm{mg} / \mathrm{kg}$ IV was given to each patient after induction of anesthesia. Once the surgery was over, neuromuscular blockade was antagonized with Inj. neostigmine $40 \mathrm{mcg} / \mathrm{kg}$ and Inj. glycopyrrolate $10 \mathrm{mcg} / \mathrm{kg}$.
The trachea was extubated when the gag reflex had returned and the patient started breathing spontaneously and showing purposeful movement of all extremities and opened the eyes. Then, the patient was placed in the lateral decubitus position. The time of discontinuing the agent was taken as "time zero" to calculate the recovery time. After extubation, patients were transferred to the recovery room. In the recovery unit, all patients were oxygenated by facemask. Heart rate, non-invasive blood pressure, and respiratory rate were recorded.

All patients were monitored continuously for

1. heart rate and respiratory rate - before induction, at induction, at incision, and throughout intraoperative period.

2. Systolic and diastolic blood pressure levels, mean arterial pressure - before induction, at induction, at incision and throughout intraoperative period.

3. $\mathrm{SPO}_{2}-$ Before induction, at induction, at incision, and throughout intraoperative period Following observations were obtained:

Time of surgery (From start to end of surgery), time of anesthesia (From the start of induction to end of surgery), time between the end of anesthesia and the spontaneous eye opening, and time between the end of anesthesia and the following of verbal commands. Time to extubation from the end of anesthesia to extubation, time between the end of anesthesia, and the orientation to his or her name and the incidence of post-operative nausea and vomiting were compared in both the groups. Patient was followed up postoperatively for $24 \mathrm{~h}$.

Sample size was calculated according to the previous reference studies where propofol based total intravenous anesthesia and sevoflurane based volatile induction and maintenance anesthesia was compared. At least 30 patients in each arm were required as calculated by Open EpiVersion 3 online software, a 10\% difference could be determined between the group at $80 \%$ power and $5 \%$ significance $(\alpha=0.05, \beta=0.80)$. The data were analyzed using Statistical Package for the Social Sciences version 21.0 for windows. Student " $\mathrm{t}$ " test was used to test for statistical significance in the differences of the two means. $\mathrm{P}<0.05$ was taken as statistically significant.

\section{Inclusion criteria}

The following criteria were included in the study:

- Assessed patients of ASA physical status I and II undergoing tonsillectomy.

- Normal biochemical and hematological parameters.

- Age group between 05 and 25 years.

- No known hypersensitivity to egg or drug.

- Airway - MPC I and II 


\section{Exclusion criteria}

The following criteria were excluded from the study:

1. Those who refused consent.

2. ASA class III and above.

3. Patients with $\mathrm{H} / \mathrm{O}$ drug or egg allergy.

4. Anticipated difficult airway.

5. $\mathrm{H} / \mathrm{O}$ serious adverse experience with anesthesia.

6. Severe $\mathrm{CVS} / \mathrm{RS} / \mathrm{CNS} /$ Metabolic disease

\section{RESULTS}

A total of 60 patients of ASA I and II between the age group of $05-25$ years of either sex posted for elective tonsillectomy were selected for the study. They were randomly divided into two groups. Group P and Group S in which Group P denotes patients who received induction and maintenance with propofol and Group S denotes patients who received induction and maintenance with sevoflurane.

In our study, $56.6 \%$ of Group P and $66.67 \%$ of Group S patients were in the age group of 5-9 years. In 10-14years age group, 36.67\% were in Group P and 20\% in Group S. About $6.67 \%$ of Group P and $13.33 \%$ of Group S were in the age group of 15-19 years. No patients were in the age group of 20-25 years. There was no significant difference in age distribution between the two groups $(\mathrm{P}>0.05)$. In Group P, 19 patients were male and 11 patients were female. In Group S, 16 patients were male and 14 patients were female. There was no any significant difference in gender distribution between the two groups $(\mathrm{P}=0.432)$. The mean weight in Group P was $21.1 \pm 5.24 \mathrm{~kg}$ while in Group S was $20.47 \pm 5.50 \mathrm{~kg}$, there was no significant difference in body weight distribution between the groups $(\mathrm{P}>0.05)$. In Group P and Group S, 26 patients were under ASA I grade and four patients were under ASA II grade. There was no statistically significant difference between ASA score among the study groups $(\mathrm{P}=1)$. In our study, duration of surgery in Group P was 41.46+3.18 min and in Group S it was $43.03+3.58 \mathrm{~min}$. This was found to be statistically not significant $(\mathrm{P}>0.05)$. Further the duration of anesthesia in Group P was 56.5+3.81 min and in Group S it was $57.2+3.04 \mathrm{~min}$ which was found to be statistically not significant $(\mathrm{P}>0.05)$ (Table 1$)$.

In our study, the eye opening in Group P patients was found to be $8.9+1.21 \mathrm{~min}$ and that in Group $\mathrm{S}$ was $6.6+1.25$ which was found to be statistically significant.

The following of verbal commands in Group P was found to occur at 10.13+1.28 min., while that in Group S was found to be at $7.63+1.25 \mathrm{~min}$, which was statistically significant.

\begin{tabular}{|c|c|c|}
\hline & $\begin{array}{c}\text { Group P } \\
\text { n (\%) }\end{array}$ & $\begin{array}{c}\text { Group S } \\
\text { n (\%) }\end{array}$ \\
\hline \multicolumn{3}{|l|}{ Age (years) } \\
\hline $5-9$ & $17(56.67 \%)$ & $20(66.67 \%)$ \\
\hline $10-14$ & $11(36.67 \%)$ & $6(20 \%)$ \\
\hline $15-19$ & $2(6.67 \%)$ & $4(13.33 \%)$ \\
\hline $20-25$ & 0 & 0 \\
\hline Mean $\pm S D$ & $9.43+2.7$ & $9.53+2.8$ \\
\hline Unpaired $t$ test and $P$ value & \multicolumn{2}{|c|}{$t=0.1408, d . f=58, P=0.89$} \\
\hline \multicolumn{3}{|l|}{ Gender distribution } \\
\hline Male & $19(63.33 \%)$ & $16(53.33 \%$ \\
\hline Female & $11(36.67 \%)$ & $14(46.67 \%$ \\
\hline Unpaired $t$ test and $P$ value & \multicolumn{2}{|c|}{$t=0.617$, d. $f=1, P=0.432$} \\
\hline \multicolumn{3}{|l|}{ Weight $(\mathrm{kg})$} \\
\hline $11-15$ & $2(6.67 \%)$ & $8(26.67 \%)$ \\
\hline $16-25$ & $21(70 \%)$ & $16(53.33 \%)$ \\
\hline $26-35$ & $7(23.33 \%)$ & $6(20 \%)$ \\
\hline Mean $\pm S D$ & $21.1+5.24$ & $20.47+5.50$ \\
\hline Unpaired $t$ test and $P$ value & \multicolumn{2}{|c|}{$\mathrm{t}=0.45$, d. $f=58, P=0.65$} \\
\hline \multicolumn{3}{|l|}{ ASA grades } \\
\hline 1 & $26(86.67 \%)$ & $26(86.67 \%$ \\
\hline II & $4(13.33 \%)$ & $4(13.33 \%)$ \\
\hline $\begin{array}{l}\text { Duration of Surgery (From } \\
\text { start to end of surgery) }\end{array}$ & $\begin{array}{r}41.46+3.18 \\
t=1.79, \text { d.f }\end{array}$ & $t=1.79$, d.f=58, $P=0.07$ \\
\hline $\begin{array}{l}\text { Duration of Anesthesia } \\
\text { anesthesia (From the start of } \\
\text { induction to end of surgery) }\end{array}$ & $\begin{array}{l}56.5+3.81 \\
t=0.79, \text { d.f }\end{array}$ & $\begin{array}{l}57.2+3.04 \\
, P=0.43\end{array}$ \\
\hline
\end{tabular}

The time for extubation in Group $\mathrm{P}$ was found to be $11.17+1.29 \mathrm{~min}$, while that in Group $\mathrm{S}$ was found to be $8.67+1.24 \mathrm{~min}$, which was statistically significant.

The duration for complete orientation in Group P was found to be $12.2+1.27 \mathrm{~min}$, while that in Group S was found to be $9.43+1.04 \mathrm{~min}$, which came out to be statistically significant (Table 2). Patients in sevoflurane group thus were found to have a faster recovery profile as compared to patients in Propofol group.

The analysis of parameters such as heart rate parameters, respiratory rate, systolic and diastolic blood pressures, mean arterial pressures, respiratory rate, and $\mathrm{SPO}_{2}$ showed that these parameters were comparable in both the groups throughout the time period extending from preinduction up to $60 \mathrm{~min}$ of induction. These parameters were compared in both the groups at an interval of 5,10 , 15, 30, 45, and $60 \mathrm{~min}$. All these parameters were found to be comparable in both the groups with no statistically significant difference in between then at any point of time $(\mathrm{P}>0.05)$ (Table 3) and (Figures 1-6).

The incidence of post-operative nausea vomiting was higher in Group S (16.67\%) than Group P (3.33\%); however, this difference was not found to be statistically significant (Table 4). 


\begin{tabular}{|c|c|c|c|}
\hline $\begin{array}{l}\text { Parameter } \\
\text { Duration } \\
\text { (minutes) }\end{array}$ & $\begin{array}{c}\text { Group P } \\
\text { Mean } \pm \text { SD } \\
\text { (In minutes) }\end{array}$ & $\begin{array}{c}\text { Group S } \\
\text { Mean } \pm \text { SD } \\
\text { (In minutes) }\end{array}$ & $\begin{array}{l}\text { Unpaired } t \text { test } \\
\text { and } P \text { value }\end{array}$ \\
\hline Eye opening & $8.9+1.21$ & $6.6+1.25$ & $\begin{array}{c}\mathrm{t}=7.24, \mathrm{~d} . \mathrm{f}=58 \\
\mathrm{P}<0.01\end{array}$ \\
\hline $\begin{array}{l}\text { Verbal } \\
\text { command }\end{array}$ & $10.13+1.28$ & $7.63+1.25$ & $\begin{array}{c}t=7.65, d . f=58 \\
P<0.01\end{array}$ \\
\hline Extubation & $11.17+1.29$ & $8.67+1.24$ & $\begin{array}{c}\mathrm{t}=7.65, \mathrm{~d} . \mathrm{f}=58 \\
\mathrm{P}<0.01\end{array}$ \\
\hline Orientation & $12.2+1.27$ & $9.43+1.04$ & $\begin{array}{c}t=9.24, d . f=58 \\
P<0.01\end{array}$ \\
\hline
\end{tabular}

\section{DISCUSSION}

Rapid emergence from anesthesia and post op recovery of cognitive function as well as hemodynamic stability is important requirements of modern anesthesia. Propofol is a short-acting general anesthetic agent used widely for total intravenous anesthesia because of its favorable recovery profile and low incidence of side effects. Propofol infusions are also becoming increasingly popular for maintenance of anesthesia. However, the use of propofol is associated with pain on injection, cardiovascular, and respiratory depression and requires an intravenous drug delivery system. ${ }^{10}$

Sevoflurane is a safe and versatile inhalational anesthetic compared with currently available agents. Sevoflurane is useful in adults and children for both induction and maintenance of anesthesia in inpatient and outpatient surgery. Of all currently used anesthetics, the physical, pharmacodynamics, and pharmacokinetic properties of sevoflurane come closest to that of the ideal anesthetic. These characteristics include inherent stability, low flammability, non-pungent odor, lack of irritation to airway, and low blood: Gas solubility allowing rapid induction of and emergence from anesthesia, minimal end-organ effects, minimal effect on cerebral blood flow, low reactivity with other drugs, and a vapor pressure and boiling point that enables delivery using standard vaporization techniques. The aim of this study was to compare the propofol based total intravenous anesthesia and sevoflurane based volatile induction and maintenance anesthesia on post-operative recovery profile in elective tonsillectomy. ${ }^{11}$

In our study, in Group P and Group S, 26 patients were under ASA I grade and four patients were under ASA II grade. There was no statistically significant difference between ASA score among the study groups $(\mathrm{P}=1)$. No statistically significant difference was determined between the groups in respect of patient characteristics and ASA scores. Findings of authors such as Fredman et al. were

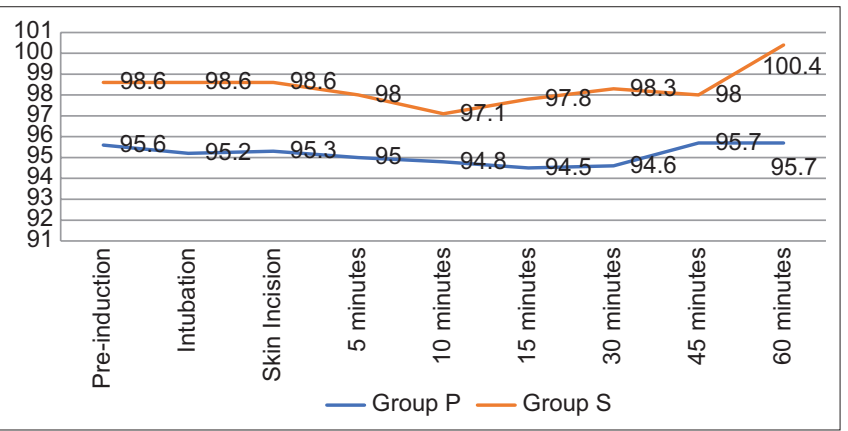

Figure 1: Comparison of mean heart rate in both the groups

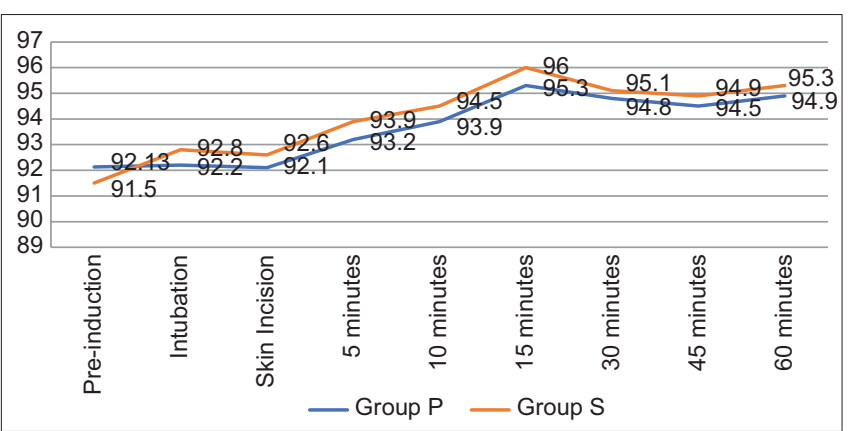

Figure 2: Comparison of mean systolic blood pressure in both the groups

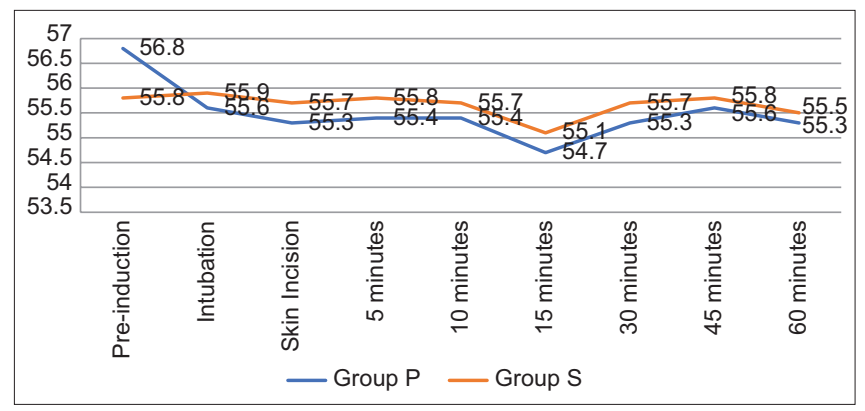

Figure 3: Comparison of mean diastolic blood pressure in both the groups

found to be comparable with our study. They also found no statistical difference in respect to patient characteristics and ASA scores. ${ }^{12}$

In our study, time taken for eye opening from termination of anesthetic was significantly shorter with sevoflurane group when compared with propofol group $(\mathrm{P}<0.01)$. In sevoflurane group, it was $6.6+1.25$ min whereas it was $8.9+1.21 \mathrm{~min}$ in propofol group. Choi et al. found that spontaneous eye opening in sevoflurane group was shorter than propofol group which is similar as our study. ${ }^{13}$

However, Shah and Adaroja study concluded that compared to propofol group (5.41 $\pm 0.99 \mathrm{~min})$, the emergence times from cessation of the administration of the anesthetic agent to spontaneous eye opening was significantly 


\begin{tabular}{|c|c|c|c|c|c|c|c|}
\hline \multirow{2}{*}{\multicolumn{4}{|c|}{$\begin{array}{l}\text { Table 3: Comparison of hemodynamic } \\
\text { parameters in both the cases }\end{array}$}} & \multicolumn{4}{|c|}{ Table 3: (Continued) } \\
\hline & & & & & \multirow{2}{*}{$\begin{array}{c}\text { Group P } \\
\text { Mean } \pm \text { SD } \\
(n=30)\end{array}$} & \multirow{2}{*}{$\begin{array}{l}\text { Group S } \\
\text { Mean } \pm S D \\
(n=30)\end{array}$} & \multirow{2}{*}{$\begin{array}{l}\text { Unpaired } t \text { test } \\
\text { and } p \text { value }\end{array}$} \\
\hline & \multirow{2}{*}{$\begin{array}{l}\text { Group P } \\
\text { Mean } \pm \text { SD } \\
(n=30)\end{array}$} & \multirow{2}{*}{$\begin{array}{l}\text { Group S } \\
\text { Mean } \pm S D \\
(n=30)\end{array}$} & \multirow[t]{2}{*}{$\begin{array}{l}\text { Unpaired } t \text { test } \\
\text { and } p \text { value }\end{array}$} & & & & \\
\hline & & & & Intubation & $67.8 \pm 6.8$ & $68.2 \pm 6.7$ & $t=0.23, d . f=58$ \\
\hline Heart rate & & & & & & & $P=0.82$ \\
\hline Pre-induction & $95.6+8.7$ & $98.6+7.7$ & $\begin{array}{c}t=1.41, \text { d.f }=58 \\
P=0.16\end{array}$ & Skin Incision & $67.5 \pm 7.2$ & $68 \pm 6.5$ & $\begin{array}{c}t=0.28, d . f=58, \\
P=0.78\end{array}$ \\
\hline Intubation & $95.2+8.1$ & $98.6+7.8$ & $\begin{array}{c}t=1.65, \text { d. } f=58 \\
P=0.10\end{array}$ & $5 \min$ & $68 \pm 6.8$ & $68.5 \pm 6.6$ & $\begin{array}{c}t=0.29, \text { d. } f=58, \\
P=0.77\end{array}$ \\
\hline Skin incision & $95.3+8.2$ & $98.6+7.4$ & $\begin{array}{c}t=1.66, d . f=58 \\
P=0.10\end{array}$ & $10 \mathrm{~min}$ & $68.2 \pm 7.1$ & $68.6 \pm 6.7$ & $\begin{array}{c}t=0.22, d . f=58, \\
P=0.82\end{array}$ \\
\hline $5 \mathrm{~min}$ & $95+7.68$ & $98+7.6$ & $\begin{array}{c}t=1.52, d . f=58 \\
P=0.13\end{array}$ & $15 \mathrm{~min}$ & $68.2 \pm 7.3$ & $68.7 \pm 6.5$ & $\begin{array}{c}t=0.28, d . f=58, \\
P=0.78\end{array}$ \\
\hline $10 \mathrm{~min}$ & $94.8+7.2$ & $97.1+6.4$ & $\begin{array}{c}t=1.3, \text { d. } f=58 \\
P=0.19\end{array}$ & $30 \mathrm{~min}$ & $68.4 \pm 8.5$ & $68.8 \pm 7.7$ & $\begin{array}{c}t=0.19, d . f=58, \\
P=0.85\end{array}$ \\
\hline $15 \mathrm{~min}$ & $94.5+8.2$ & $97.8+8.2$ & $\begin{array}{c}t=1.56, d . f=58 \\
P=0.12\end{array}$ & $45 \mathrm{~min}$ & $68.5 \pm 8.96$ & $68.8 \pm 8.8$ & $\begin{array}{c}t=0.13, d . f=58, \\
P=0.89\end{array}$ \\
\hline $30 \mathrm{~min}$ & $94.6+7.8$ & $98.3+8.3$ & $\begin{array}{c}t=1.78, \text { d.f }=58 \\
P=0.08\end{array}$ & $60 \mathrm{~min}$ & $68.5 \pm 9.7$ & $68.8 \pm 8.2$ & $\begin{array}{c}t=0.13, d . f=58, \\
P=0.89\end{array}$ \\
\hline $45 \mathrm{~min}$ & $95.7+7.5$ & $98+7.4$ & $\begin{array}{c}t=1.20, \text { d.f }=58 \\
P=0.24\end{array}$ & $\begin{array}{l}\text { Respiratory } \\
\text { rate }\end{array}$ & & & \\
\hline $60 \mathrm{~min}$ & $95.7+7.8$ & $100.4+6.9$ & $\begin{array}{c}t=2.47, \text { d.f }=58 \\
P=0.01\end{array}$ & Pre-induction & $14.9+0.4$ & $14.7+0.7$ & $\begin{array}{c}t=1.36, d f=58, \\
P=0.18\end{array}$ \\
\hline $\begin{array}{l}\text { Systolic blood } \\
\text { pressures }\end{array}$ & & & & Intubation & $14.6+0.6$ & $14.7+0.6$ & $\begin{array}{c}t=0.64, \text { d. } f=58, \\
P=0.52\end{array}$ \\
\hline Pre-induction & $92.13 \pm 8.2$ & $91.5 \pm 7.4$ & $\begin{array}{c}t=0.31 \text { d. } f=58 \\
P=0.75\end{array}$ & Skin incision & $14.8+0.4$ & $14.6+0.7$ & $\begin{array}{c}t=1.35, d \cdot f=58, \\
P=0.18\end{array}$ \\
\hline Intubation & $92.2 \pm 7.3$ & $92.8 \pm 7.1$ & $\begin{array}{c}t=0.32 \text { d.f }=58 \\
P=0.74\end{array}$ & $5 \mathrm{~min}$ & $14.8+0.5$ & $14.9+0.4$ & $\begin{array}{c}t=0.85, \text { d. } f=58, \\
P=0.39\end{array}$ \\
\hline Skin incision & $92.1 \pm 7.5$ & $92.6 \pm 6.9$ & $\begin{array}{c}t=0.27 \text { d. } f=58 \\
P=0.78\end{array}$ & $10 \mathrm{~min}$ & $14.7+0.7$ & $14.8+0.5$ & $\begin{array}{c}t=0.63, d . f=58, \\
P=0.52\end{array}$ \\
\hline $5 \mathrm{~min}$ & $93.2 \pm 7.8$ & $93.9 \pm 7.6$ & $\begin{array}{c}t=0.35 \text { d. } f=58 \\
P=0.73\end{array}$ & $15 \mathrm{~min}$ & $14.8+0.5$ & $14.7+0.6$ & $\begin{array}{c}\mathrm{t}=0.70, \mathrm{~d} . \mathrm{f}=58, \\
P=0.48\end{array}$ \\
\hline $10 \mathrm{~min}$ & $93.9 \pm 7.6$ & $94.5 \pm 6.7$ & $\begin{array}{l}t=0.32 \text { d.f }=58 \\
P=0.75\end{array}$ & $30 \mathrm{~min}$ & $14.9+0.3$ & $14.7+0.7$ & $\begin{aligned} & P=0.48 \\
t= & 1.4, d . f=58 \\
P & =0.15\end{aligned}$ \\
\hline $15 \mathrm{~min}$ & $95.3 \pm 7.5$ & $96 \pm 6.45$ & $\begin{array}{c}t=0.39 \text { d.f }=58 \\
P=0.69\end{array}$ & $45 \mathrm{~min}$ & $14.7+0.7$ & $14.8+0.5$ & $\begin{array}{c}t=0.63, \text { d. } f=58, \\
P=0.52\end{array}$ \\
\hline $30 \mathrm{~min}$ & $94.8 \pm 7.9$ & $95.1 \pm 6.9$ & $\begin{array}{c}\mathrm{t}=0.16 \text { d. } f=58 \\
\mathrm{P}=0.87\end{array}$ & $60 \mathrm{~min}$ & $14.8+0.6$ & $14.9+0.3$ & $\begin{array}{c}t=0.82, d . f=58, \\
P=0.42\end{array}$ \\
\hline $60 \mathrm{~min}$ & $94.9 \pm 9.5$ & $95.3 \pm 7.1$ & $\begin{array}{c}t=0.17 d . f=58 \\
P=0.86 \\
t=0.37 \text { d. } f=58 \\
P=0.71\end{array}$ & $\begin{array}{l}\mathrm{SPO}_{2} \\
\text { Pre-induction }\end{array}$ & $99.9+0.3$ & $99.9+0.3$ & $\begin{array}{c}t=00, d \cdot f=58 \\
P=1\end{array}$ \\
\hline $\begin{array}{l}\text { Diastolic blood } \\
\text { pressure }\end{array}$ & & & & Intubation & $99.9+0.4$ & $99.7+0.6$ & $\begin{array}{c}t=1.52, d . f=58, \\
P=0.13\end{array}$ \\
\hline Pre-induction & $56.8 \pm 7.9$ & $55.8 \pm 7.5$ & $\begin{array}{c}t=0.50 \text { d. } f=58 \\
P=0.62\end{array}$ & Skin incision & $99.8+0.4$ & $99.7+0.5$ & $\begin{array}{c}t=0.86, d . f=58, \\
P=0.4\end{array}$ \\
\hline Intubation & $55.6 \pm 7.17$ & $55.9 \pm 7.2$ & $\begin{array}{c}t=0.16 \text { d. } f=58 \\
P=0.87\end{array}$ & $5 \mathrm{~min}$ & $99.9+0.4$ & $99.8+0.5$ & $\begin{array}{c}t=0.86, d . f=58, \\
P=0.4\end{array}$ \\
\hline Skin Incision & $55.3 \pm 7.6$ & $55.7 \pm 6.9$ & $\begin{array}{c}t=0.21 \text { d. } f=58 \\
P=0.83\end{array}$ & $10 \mathrm{~min}$ & $99.7+0.6$ & $99.7+0.5$ & $\begin{array}{c}t=00, d . f=58 \\
P=1\end{array}$ \\
\hline $5 \mathrm{~min}$ & $55.4 \pm 6.9$ & $55.8 \pm 6.7$ & $\begin{array}{c}t=0.23 \text { d. } f=58 \\
P=0.82\end{array}$ & $15 \mathrm{~min}$ & $99.9+0.3$ & $99.7+0.6$ & $\begin{array}{c}t=1.63, d . f=58, \\
P=0.11\end{array}$ \\
\hline $10 \mathrm{~min}$ & $55.4 \pm 7.6$ & $55.7 \pm 7.4$ & $\begin{array}{c}t=0.15 \text { d. } f=58 \\
P=0.87\end{array}$ & $30 \mathrm{~min}$ & $99.8+0.6$ & $99.9+0.5$ & $\begin{array}{c}t=0.70, d \cdot f=58, \\
P=0.49\end{array}$ \\
\hline $15 \min$ & $54.7 \pm 7.7$ & $55.1 \pm 6.9$ & $\begin{array}{c}t=0.21 \text { d. } f=58 \\
P=0.83\end{array}$ & $45 \mathrm{~min}$ & $99.7+0.5$ & $99.7+0.5$ & $\begin{array}{c}t=00, \text { d. } f=58 \\
P=1\end{array}$ \\
\hline $30 \mathrm{~min}$ & $55.3 \pm 9.4$ & $55.7 \pm 8.6$ & $\begin{array}{l}t=0.17 \text { d. } f=58 \\
P=0.86 \\
t=0.08 \text { d. } f=58\end{array}$ & $60 \mathrm{~min}$ & $99.8+0.5$ & $99.7+0.6$ & $\begin{array}{c}t=0.70, d . f=58, \\
P=0.48\end{array}$ \\
\hline
\end{tabular}

shorter in the sevoflurane group $(2.86 \pm 0.66 \mathrm{~min})$ which corresponds to our study. ${ }^{14}$

In our study, time taken for following the verbal commands was significantly shorter with Group $S$ when compared with Group $\mathrm{P}(\mathrm{P}<0.01)$. In Group $\mathrm{S}$ it was $7.63+1.25 \mathrm{~min}$
$55.5 \pm 9.2 \quad t=0.08$ d. $f=58$
$P=0.94$

Mean arterial pressures

Pre-induction $\quad 68.6 \pm 7.7 \quad 67.7 \pm 7.1 \quad t=0.47$, d. $f=58$, $P=0.64$

(Contd...) 


\begin{tabular}{|c|c|c|}
\hline $\begin{array}{l}\text { Post-operative } \\
\text { nausea and vomiting }\end{array}$ & $\begin{array}{l}\text { Group P } \\
\text { n (30) }\end{array}$ & $\begin{array}{l}\text { Group S } \\
\mathrm{n}(30)\end{array}$ \\
\hline Present & $1(3.33 \%)$ & $5(16.67 \%)$ \\
\hline Absent & $29(96.67 \%)$ & $25(83.33 \%)$ \\
\hline Chi-square and $P$ value & \multicolumn{2}{|c|}{$\chi^{2}=2.96, d . f=1, P=0.09$} \\
\hline
\end{tabular}

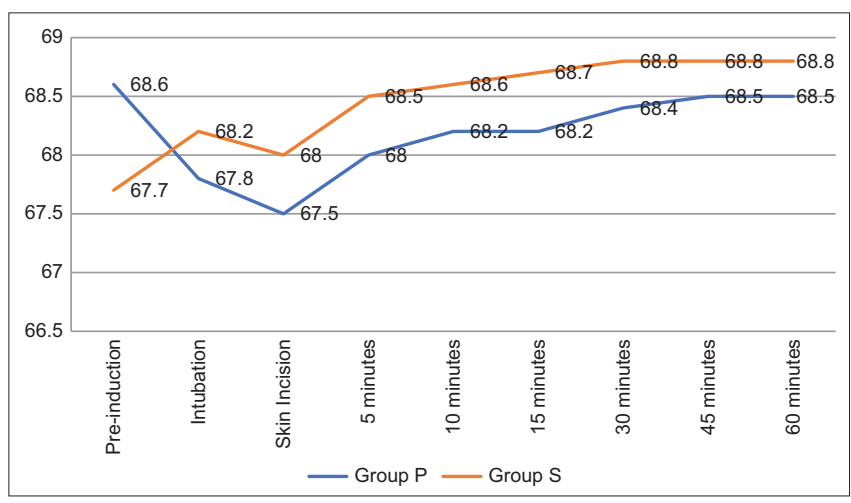

Figure 4: Comparison of mean arterial pressure in both the groups

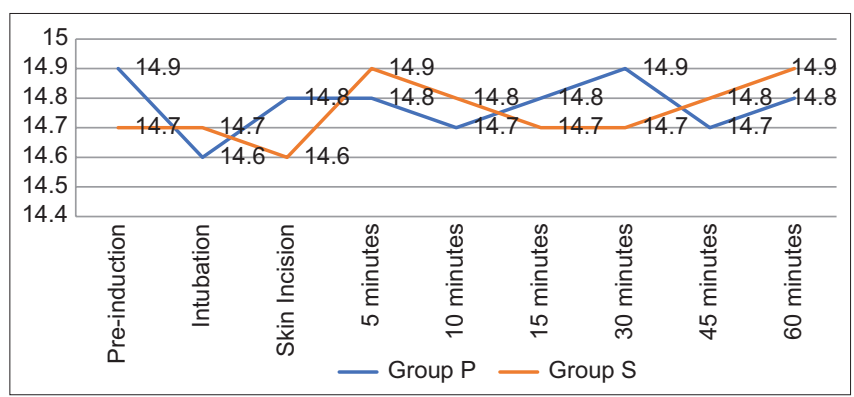

Figure 5: Comparison of mean respiratory rate in both the groups

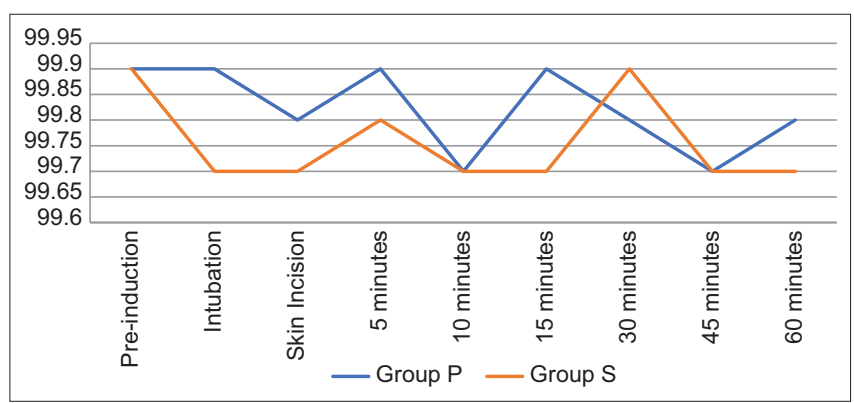

Figure 6: Comparison of mean $\mathrm{SPO}_{2}$ levels in both the groups

whereas it was $10.13+1.28 \mathrm{~min}$ in Group P. Shorter mean time to following of verbal commands with sevoflurane may be due to rapid drug elimination. Singh et al. reported that time to follow verbal commands was significantly shorter in Group S $(7.87 \pm 0.83 \mathrm{~min})$ than Group P (11.88 $\pm 1.30 \mathrm{~min}$ ) which was similar to our study. ${ }^{15}$ Orhon et al. found that Group S obeyed verbal commands earlier as compare to Group P $(\mathrm{P}<0.05)$ which corresponds with our study. ${ }^{16}$
In our study, the sevoflurane group took significantly shorter time for extubation when compared with the propofol group. The time was $8.67+1.24 \mathrm{~min}$ in Group S and 11.17+1.29 min in Group P $(\mathrm{P}<0.01)$. Shorter mean time to extubation with sevoflurane may be due to rapid drug elimination after tapering off sevoflurane. In a similar study Bharti et al. concluded that extubation time was not significantly different between Group P $(8.5 \pm 4.3 \mathrm{~min})$ and Group S (9.3 $\pm 3.7 \mathrm{~min}$ ), which was not similar to our study. ${ }^{17}$

Time taken for orientation in Group P was 12.2+1.27 min and in Group $\mathrm{S}$ was $9.43+1.04$ min. It was significantly shorter in sevoflurane group as compare to propofol group $(\mathrm{P}<0.01)$. Ebert et al. 67 found that patient orientation to his/her name was shorter in Group S (12.2 min) than Group P (13.1 min), which was similar to our study. ${ }^{18}$

The intraoperative hemodynamic variables (heart rate, systolic blood pressure, diastolic blood pressure, and mean arterial blood pressure) were monitored in all patients and were maintained within baseline values in both the Group P and the Group $S$ by adjusting the maintenance anesthetic concentration. There were no significant differences in the intraoperative hemodynamics of both the sevoflurane and the propofol groups. Ahila and Asokan found that the mean values of mean arterial pressure between the Group P and Group S were observed to be statistically not significant, which was similar to our study. ${ }^{19}$

The incidence of post-operative nausea vomiting was higher in Group S (16.67\%) than Group P (3.33\%) but it was statistically not significant $(\mathrm{P}=0.09)$. Tang et al. concluded that post-operative nausea and vomiting were much less in propofol group than sevoflurane group and statistically significant as well $(\mathrm{P}<0.05)$ which was similar to our study. ${ }^{20}$

\section{Limitations of the study}

One of the limitation of our study was that the study was done in young patients undergoing single type of surgery ie tonsillectomy. Studies on relatively older patients undergoing various surgeries are needed to further understand differences in intraoperative hemodynamics.

\section{CONCLUSION}

Sevoflurane as an anesthetic agent is associated with reduced time for spontaneous eye opening and for following verbal commands. Moreover, sevoflurane group took significantly shorter time for extubation when compared with the propofol group. Thus, we conclude that sevoflurane is a useful alternative to propofol in providing anesthesia where rapid emergence and recovery of cognitive functions are desired. 


\section{ACKNOWLEDGMENT}

The authors acknowledge department of anesthesiology, Dr shankarrao chavan government medical college and hospital nanded for extending its valuable support in undertaking this study.

\section{REFERENCES}

1. Wetmore RF. Surgical management of the tonsillectomy and adenoidectomy patient. World J Otorhinolaryngol Head Neck Surg. 2017;3(3):176-182.

http://doi.org/doi:10.1016/j.wjorl.2017.01.001

2. Ravi R and Howell T. Anaesthesia for paediatric ear, nose, and throat surgery. Contin Educ Anaesth Crit Care Pain. 2007;7(2):33-37. https://doi.org/10.1093/bjaceaccp/mkm004

3. Johnston $\mathrm{J}$, McLaren $\mathrm{H}$, Mahadevan $\mathrm{M}$ and Douglas RG. Clinical characteristics of obstructive sleep apnea versus infectious adenotonsillar hyperplasia in children. Int $\mathrm{J}$ Pediatr Otorhinolaryngol. 2019;116:177-180.

https://doi.org/10.1016/j.jporl.2018.11.004

4. Darrow DH and Siemens C. Indications for tonsillectomy and adenoidectomy. Laryngoscope. 2002;112(8 Pt 2 Suppl 100):6-10.

https://doi.org/10.1002/lary.5541121404

5. American Society of Anaesthesiologists Committee of Ambulatory Surgical Care, Approved by the ASA House of Delegates on October 15, 2003, Last Amended on October 22, 2008, and Reaffirmed on October 17, 2018); 2003.

6. Dong C, Sun P, Yu J, Zhang J and Wu C. Clinical comparison of induction with inhalational sevoflurane versus intravenous propofol for perioperative anesthetics in adult: A randomized clinical trial. Clin Pract. 2017;18(7):349-362.

7. Kulkarni S, Harsoor SS, Chandrasekar M, Bhaskar SB, Bapat J, Ramdas EK, et al. Consensus statement on anaesthesia for day care surgeries. Indian J Anaesth. 2017;61(2):110-24.

https://doi.org/10.4103/ija.IJA_659_16

8. Gyulaházi J, Varga K, Iglói E, Redl P, Kormos J and Fülesdi B. The effect of preoperative suggestions on perioperative dreams and dream recalls after administration of different general anaesthetic combinations: A randomized trial in maxillofacial surgery. BMC Anaesthesiol. 2015;15(1):11.

https://doi.org/10.1186/1471-2253-15-11

9. Kocaturk O, Kaan N, Kayacan N and Ertugrul F. The incidence of postoperative residual curarization following the use of intermediate-acting muscle relaxants and related factors. Middle
East J Anaesthesiol. 2014;22(6):583-90.

10. Marik PE. Propofol: Therapeutic indications and side-effects. Curr Pharm Des. 2004;10(29):3639-3649.

https://doi.org/10.2174/1381612043382846

11. Stachnik J. Inhaled anaesthetic agents. Am J Health Syst Pharm. 2006;63(7):623-634. https://doi.org/10.2146/ajhp050460

12. Fredman B, Nathanson $\mathrm{MH}$, Smith I, Wang J, Klein $\mathrm{K}$ and White P. Sevoflurane for outpatient anaesthesia: A comparison with propofol. Anaesth Analg. 1995;81(4):823-828. https://doi.org/10.1097/00000539-199510000-00028

13. Choi ES, Shin JY, Oh AY, Park HP, Hwang JW, Lim YJ, et al. Sevoflurane versus propofol for interventional neuroradiology: A comparison of the maintenance and recovery profiles at comparable depths of anaesthesia. Korean J Anesthesiol. 2014;66(4):290-294. https://doi.org/10.4097/kjae.2014.66.4.290

14. Shah A and Adaroja RN. Comparison of haemodynamic changes with propofol and sevoflurane anaesthesia during laparoscopic surgery. Natl J Med Res. 2011;1(2):76-79.

15. Singh $Y$, Singh AP, Jain G, Yadav $G$ and Singh DK. Comparative evaluation of cost effectiveness and recovery profile between propofol and sevoflurane in laparoscopic cholecystectomy. Anesth Essays Res. 2015;9(2):155-160. https://doi.org/10.4103/0259-1162.156290

16. Orhon ZN, Devrim S, Celik M, Dogan Y, Yildirim A and Basok EK. Comparison of recovery profiles of propofol and sevoflurane anaesthesia with bispectral index monitoring in percutaneous nephrolithotomy. Korean J Anesthesiol. 2013;64(3):223-228. https://doi.org/10.4097/kjae.2013.64.3.223

17. Bharti N, Chari $P$ and Kumar P. Effect of sevoflurane versus propofolbased anaesthesia on the hemodynamic response and recovery characteristics in patients undergoing microlaryngeal surgery. Saudi J Anaesth. 2012;6(4):380-384. https://doi.org/10.4103/1658-354X.105876

18. Ebert TJ, Robinson BJ, Uhrich TD, Mackenthun A and Pichotta PJ. Recovery from sevoflurane anaesthesia: A comparison to isoflurane and propofol anaesthesia. Anaesthesiology. 1998;89(6):1524-1531. https://doi.org/10.1097/00000542-199812000-00032

19. Ahila R and Asokan G. Comparison of induction and recovery characteristics of Propofol and Sevoflurane in daycare adult tonsillectomies. IAIM. 2019;6(3):156-163.

20. Tang J, Chen L, White PF, Watcha MF, Wender RH, Naruse R, et al. Recovery profile, costs, and patient satisfaction with propofol and sevoflurane for fast-track office-based anaesthesia. Anaesthesiology. 1999;91(1):253-261. https://doi.org/10.1097/00000542-199907000-00034

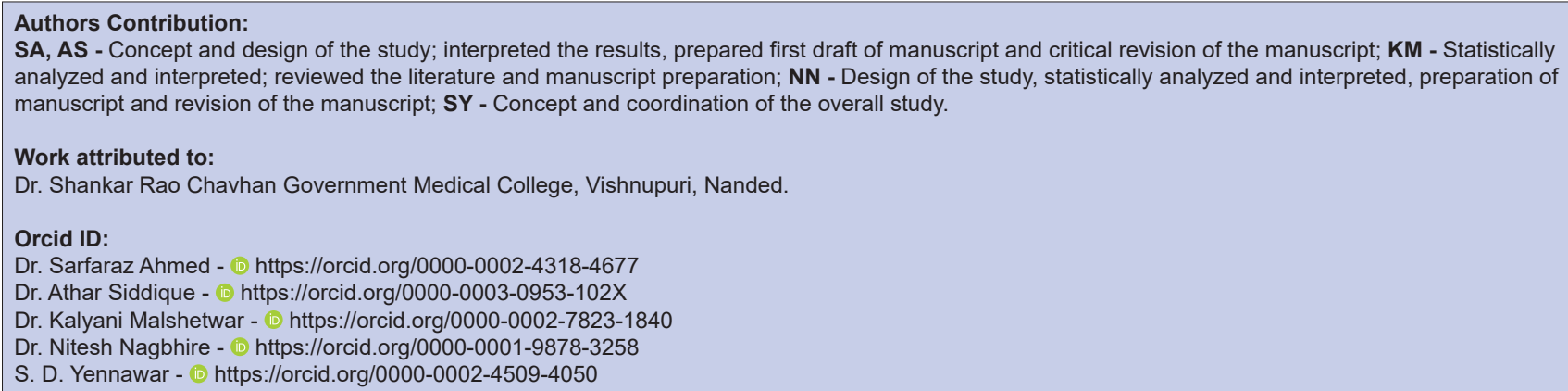

